\title{
A Study of Fertilizer Distribution System for Agriculture using Wireless Sensor Network
}

\author{
Santosh T. Warpe \\ Research Scholar \\ Department of Computer \\ Science and Engineering \\ RKDF University \\ Bhopal, M.P., India
}

\author{
Ravi Singh Pippal \\ Professor \\ Department of Computer \\ Science and Engineering \\ RKDF University \\ Bhopal, M.P., India
}

\begin{abstract}
This paper presents study of Wireless Sensor Network that applied in agriculture for automated farming. In this paper, a survey on Wireless Sensor Network and technologies carried out. Based on the survey, the need for automated distribution of fertilizer system especially in developing country like India is required. This can help the end users like farmers for the better understanding of agriculture practices to be adopted for distribution of fertilizers.
\end{abstract}

\section{Keywords}

Fertilizer, Wireless Sensor Network, Nitrogen, phosphorus, potassium, energy efficiency

\section{INTRODUCTION}

Considering the terminology for fertilizer, it can be easily stated that a material either artificial/synthetic or natural origin used to nourish roots as well as develop immune system to fight against diseases with the result of plant's growth. Encountering factors of dependability for fertilizers are organic stuffs like seaweed and natural precursors like soil fertility. The use of fertilizers for agriculture in India has risen immensely in the last 60 years. In many parts of the country, cultivated Indo-Gangetic plains resulting in deterioration of soil health deucedly [1].

In farm soils the most commonly insufficient nutrients are Nitrogen, phosphorus and potassium, abbreviated as N, P, K respectively. The three nutrients should be applied in a balanced ratio corresponding the needs of the each particular type of soil otherwise crop yields by deficiency of nutrients and only will attain the level which is permitted by the most deficient nutrient, Ahmed et al. [2]. If farmers use automated fertilizer distribution system, this problem can be perfectly rectified using wireless application. Fig 1 shows the different fertilizer distribution approaches used in different countries.

\section{WIRELESS SENSOR NETWORK}

Wireless Sensor Network (WSN) is an ad-hoc fashion arrangement of strewed sensors across network in Layman's term. To get relevant results and sense physical phenomenon,

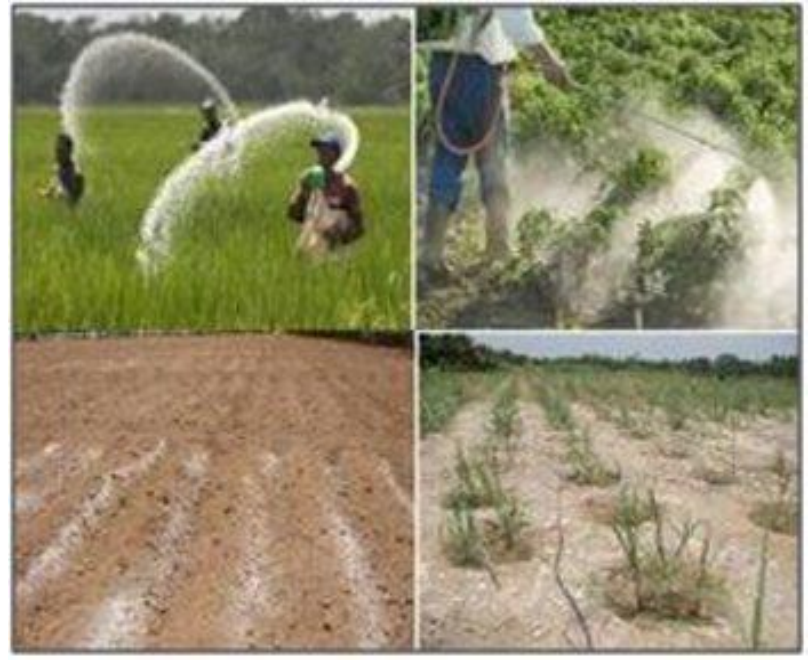

Fig 1: Fertilizer distribution

these sensors work together by conglomerating the information required to process. A WSN comprise of protocols and algorithms with self-organizing mettle. Wireless sensor networks mainly use, broadcast communication while $\mathrm{P} 2 \mathrm{P}$ mode of didacticism gets used by ad hoc networks. What separates the wireless sensor networks from ad hoc networks are the sensor nodes number crunching capability, Energy and Sensors limited power. Due to the large number of sensors and amount of overhead, it may not have global ID. Applications of WSN include monitoring of objects, monitoring of an area, Monitoring of both area and objects.

Some examples in regard are given below.

a) Habitat monitoring (Plants, animals) and environmental monitoring, weather forecasting systems.

b) Medical Applications (Patient, Doctor follow ups, monitoring of physiological condition of patients)

c) Power supply and transfer systems (in Production, distribution and consumption buildings)

d) Home and Office Applications.

e) Analyzing of remote locations and positions (Tornedo movements, detection of forest fires etc.)

f) Monitoring of the traffic by placing sensors in taxis in a broad metropolitan area and planning of routes based on these observations. 
g) Determination of empty and full spaces in a parking lot.

h) Provision of security in facilities such as Shopping centers, car parks and similar by means of Wireless Surveillance Sensor Networks.

i) Military sensor networks for Detection, finding and monitoring of enemy movements.

j) Sensor networks increasing quick-wittedness against terrorist attacks.

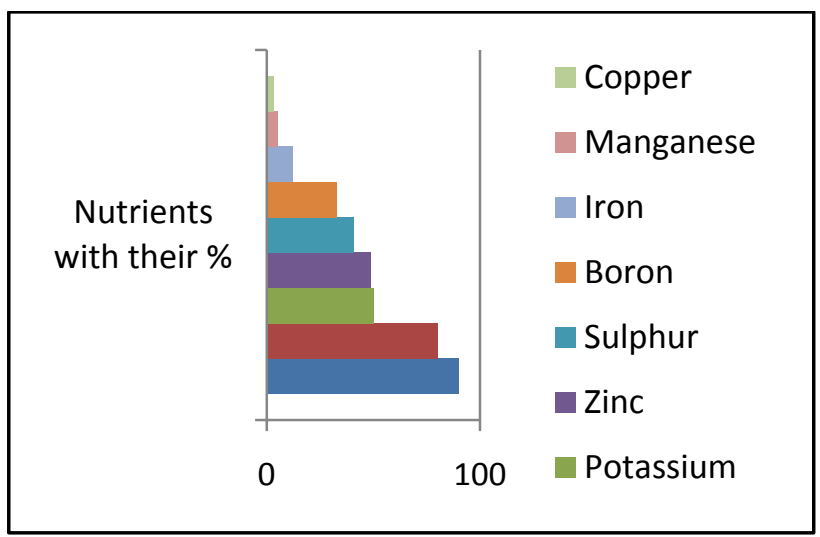

Fig 2: Deficiency in Soil

Fig. 2 shows the deficiency of nutrient in the soil and Fig. 3 shows the demand for fertilizer during the year 2010-2014.

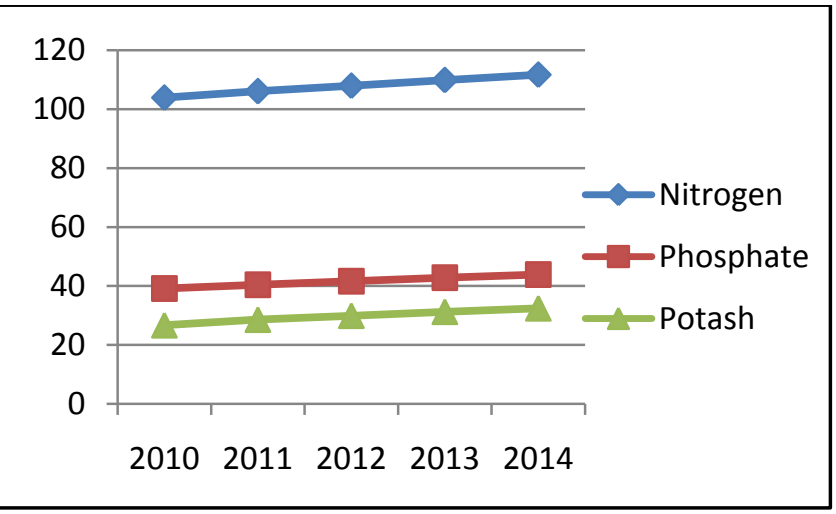

Fig 3: World demand for Fertilizer Nutrients in 2010-14 (in million tons)

\section{LITERATURE REVIEW}

Subaedah et al. [3] analyze the effect of fertilization of N, P and application of green manure of crotalaria to multiply yield of maize plant in marginal dry land. Chun et al. [4] proposed that N-P-K containing fertilizers ratios are the most limiting factors in crop production. $\mathrm{N}$ often affects the amino acid composition of protein and in turn its nutritional quality. Hence effort was made to evaluate the influence of different proportions of nutrient solutions containing N-P-K on the Glucosinolates profiles of rocket salad (Eruca sativa Mill).

Udvardi et al. [5] shows that how nitrogen impacts on environment and different strategies to avoid the effects. Deluxe et al. [6] proposed that how quantitative and comparative phylogenomics and phylogenetics will generate relevant lists of traits and genomic features associated with nitrogen-fixing mutualism. Smith et al. [7] addresses the issue in china for excessive use of fertilizer through comparative reviews. Political', 'policy', 'structural' and 'behavioral' barriers to improved fertilizer management and extenuation of DWPA are identified, along with priority agendas for policy and further research. Patil et al. [8] assessed the water productivity (WP) for annual and biennial crops cultivated under centre pivot irrigation located over desolate areas of the Al-Kharj region in Saudi Arabia. Annual crops are (wheat, barley, and corn) and biennial (alfalfa and Rhodes grass). The Surface Energy Balance Algorithm for Land (SEBAL) was applied to Advanced Space borne Thermal Emission and Reflection Radiometer (ASTER) images to obtain evapotranspiration (ET) for assessing WP and irrigation performance (IP) of crops.

Niemiec et al. [9] determined the efficiency of celeriac fertilization with phosphorus and potassium under conditions of combined plant production with NPK content of $18 \%, 5 \%$ and $11 \%$ respectively. Toth et al. [10] assessed different $\mathrm{P}$ tests for fertilizer testimonial used in Europe and confirmed their effectiveness. The first step includes soil testing to judge the crop available $\mathrm{P}$ pool in soil. The second test involves relating results from the before light soil tests to yield response to account similarly to already mentioned Brazilian system, for a $90 \%$ maximum output per year. Based on these outcomes, threshold values are often developed to divide soils into 3 different classes, "low", "medium", "high" and sometimes "surplus". From these categories the third step takes place, that is, the actual $\mathrm{P}$ recommendation is calculated.

Xiong et al. [11] study provided visual evidence of a nitrogen effect on starch granules (SGs) in pale yellow endosperm. Winter pale yellow (Titicumaestivum L.) cultivar Xumai30 was cultured under no nitrogen (control) and $240 \mathrm{kgha}-1$ of nitrogen applied at the booting stage. Gikonyo et al. [12] examine the two OCP NPS products tested against fertilizers applied to maize, soybean and climbing beans have shown good effects on the yields of crops grown and equated well with the fertilizers usually applied on them. Devadas et al. [13] described experiments designed to inquire the agronomic response to the interaction of various levels of $\mathrm{N}$ application and stripe rust severity in wheat varieties differing in response.

Salih et al. [14] determined the impact of the potassium, boron and zinc on the nitrogen of fiber. Two kenaf varieties namely; FHH 925 and 4383, were planted. Fertilizers (0, 100 and 150), (0, 1.0 and 1.5) and $(0$ and 5.0$) \mathrm{kg} / \mathrm{ha}$, for potassium, boron and zinc were added respectively. Based on the results potassium was really suitable for the kenaf. XIAO et al. [15] shows that how we can obtain the optimal drainage time at each development stage by examining the changes of nitrogen and phosphorus of a flooded paddy water system after fertilizer application. Four treatments with different water level management methods at each growth stage were conducted under the condition of ten-day continuous flooding.

Hussain [16] shows that the improvements made to improve the reliability of Nitrophosphate plant. Bao-guo et al. [17] study concludes that traditionally excess fertilizations can result in the $\mathrm{N}, \mathrm{P}$ loss from paddy field and water excessive nutrient in rice-wheat rotation areas of high fertility and the $\mathrm{N}$, $\mathrm{P}$ loss is the most in the soil applying overindulgence chemical fertilizers and manure in rice-wheat rotation areas. Kalaivani et al. [18] shows that how Zigbee based wireless sensor network applied in agriculture for intelligent farming. Lin et al. [19] proposed that how wireless network physiological signal and field signal monitoring systems in home care technology and precision agriculture useful such as monitoring physiological signals such as heart rate, ECG, and body temperature as well as temperature and moisture in air 
and soil, $\mathrm{CO} 2$, and elucidation signals in the field. Wireless transmission is the major concern while transmitting data to other end. Not only to finish and solve wireless transmission problem but also transmission and receiving between mobile unit and web server which is useful in replacing cables of physiological signal monitoring system, Bluetooth technique is used.

Sahota et al. [20] presented the design of MAC and network layers in a WSN for network application for precision agriculture that requires periodic collection of data from fixed locations. The MAC layer is contrived to save energy during the wake-up synchronization phase. The network layer is designed in such a way that, it can fit the preconditions of the application, namely periodic data collection from fixed locations, and to denigrate the energy consumption through balancing the communication load. Verma et al. [21] proved that how WSN monitors the air temperature, mugginess and completely surrounding light in brinjal field. Also, in order to conserve power and increase the lifetime of WSN, periodical sleep and wakeup modes used. Kindreda et al. [22] investigated the changes in pale yellow size, protein concentration, protein quality and AY in response to applied N. Another study shows by Daniel and Triboi [23] that the effects of two major environmental factors, temperature and nitrogen supply, on weight, protein content and especially gliadin items and constitution were studied with a new sequential extraction method coupled with RP-HPLC separations.

\section{CONCLUSION \& FUTURE SCOPE}

Fertilizer distribution is an important class of sensor network application with enormous potential benefits for the farmers and community as a whole. Till now many papers are published on various issues in fertilizer distribution and its WSN applications. Some of authors worked on effect of $\mathrm{N}, \mathrm{P}, \mathrm{K}$ on soil properties such as temperature, moisture, volumetric water content of the soil for proper fertilizer distribution as well as to monitor production process and to increase the yield of the farm. This paper presents study of Wireless Sensor Network that monitors the fertilizer values and if needed supply required fertilizer so that low cost, low power and less complex methodology can be achieved to automate Fertilizer distribution system for optimum utilization of available fertilizer and to increase the overall profit, with less human efforts.

In future, supply of fertilizers other than Nitrogen, Phosphorus $\&$ Potassium such as zinc, boron, sulphate and urea etc. is also planned Apart from this; system can be further developed for automated detection of natural ingredients of air as well as water.

\section{ACKNOWLEDGMENTS}

The authors would like to thank RKDF University, Bhopal, India for providing their academic support.

\section{REFERENCES}

[1] "Fertilizer use on the rise in India, soil health deteriorating",http://www.thehindu.com/scitech/agricultu re/fertiliser-use-on-the-rise-in-india-soil-healthdeteriorating/article1561218.ece, 2011

[2] Saleem Ahmed, Ram Sewak, Ernst W. Mutert, Hong Chi Lin, "The Appropriate Use of Fertilizers", FFTC International Seminar (Food \& fertilizer Centre), 1995

[3] Siti Subaedah, A. Aladin, and Nirwana, "Fertilization of Nitrogen, Phosphor and Application of Green Manure of
Crotalaria juncea In Increasing Yield of Maize In Marginal Dry Land", Agriculture and Agricultural Science Procedia, 9:20-25, 2016

[4] Jin-Hyuk Chun, Silbia Kim, Mariadhas Valan Arasu, Naif Abdullah Al-Dhabi, Doug Young Chun, Sun-Ju Kim, "Combined effect of Nitrogen, Phosphorus and Potassium fertilizers on the contents of glucosinolates in rocket salad", Saudi Journal of Biological Sciences, 2015

[5] Michael Udvardi, Eoin L. Brodie and William Rileyb, Shawn Kaeppler, and Jonathan Lynch, "Impacts of agricultural nitrogen on the environment and strategies to reduce these impacts", Procedia Environmental Sciences, 29:303, 2015

[6] Pierre-Marc Deluxe, Guru Radhakrishnan and Giles Oldroyd, "Tracing the evolutionary path to nitrogenfixing crops", Current Opinion in Plant Biology, 26:9599, 2015

[7] L.E.D. Smith, G. Siciliano, "A comprehensive review of constraints to improved management of fertilizers in China and mitigation of diffuse water pollution from agriculture", Agriculture, Ecosystems and Environment, 209:15-25, 2015

[8] Virupakshagowda C. Patil, Khalid A. Al-Gaadi, Rangaswamy Madugundu, ElKamil H. M. Tola, Samy Marey, Ali Aldosari, Chandrashekhar M. Biradar, and Prasanna H. Gowda, "Assessing Agricultural Water Productivity in Desert Farming System of Saudi Arabia", IEEE Journal of Selected Topics In Applied Earth Observations and Remote Sensing, 8(1):284-296, 2015

[9] Marcin Niemiec, Michał Cupiał, Anna Szeląg-Sikora, "Efficiency of celeriac fertilization with phosphorus and potassium under conditions of integrated plant production", Agriculture and Agricultural Science Procedia , 7:184-191, 2015

[10] Gergely Toth, Rannveig-Anna, Guicha rnaud, Brigitta Toth, Tamas Hermann, "Phosphorus levels in croplands of the European Union with implications for P fertilizer use", European Journal of Agronomy, 55:42-52, 2014

[11] Fei Xiong, Xurun Yu, Liang Zhou, Jing Zhang, Yanping Jin, Dongliang Li, Zhong Wang, "Effect of nitrogen fertilizer on distribution of starch granules in different regions of wheat endosperm", The Crop Journal, 2:4654,2014

[12] Gikonyo E.W, Cisse L, N. Mangale, A. Mumbuaand C. Kibunja, "Efficacy of two sulphur fertilizers on some crops in Smallholder farming in Kenya", Procedia Engineering, 83:354-364, 2014

[13] Rakhesh Devadas, Steven Dorfer, David Backhouse, David W. Lamb, "Effect of stripe rust on the yield response of wheat to nitrogen", The Crop Journal, 2:201-206, 2014

[14] Rabar Fatah Salih, Khalina Abdan, Aimrun Wayayok, Anuar Abdul Rahim, Norhashila Hashim, "Response of Nitrogen Content for Some Varieties of Kenaf Fiber (Hibiscus cannabinusL.) by Applying Different Levels of Potassium, Boron and Zinc", Agriculture and Agricultural Science Procedia , 2:375-380, 2014

[15] Meng-hua, XIAO, Shuang-en YU, Yan-yan WANG, Rong HUANG, "Nitrogen and phosphorus changes and optimal drainage time of flooded paddy field based on 
environmental factors", Water Science and Engineering, 6(2):164-177, 2013

[16] Iltifat Hussain, "The Operating experience of Nitrophosphate Plant", Procedia Engineering, 46:172177, 2012

[17] MA Bao-guo, Li Wenhua, Wang Huiyong, "Effect of different fertilizations on the N, P loss in rice-wheat rotation soil in south Hebei, China", Procedia Engineering, 28:640-643, 2012

[18] T. Kalaivani, A. Allirani, P. Priya, "A Survey on Zigbee Based Wireless Sensor Networks in Agriculture", 3rd International Conference on Trendz in Information Sciences and Computing, 85-89, 2011

[19] Zau-Sheng Lin, Yi-Ying Chang, Chun-Zu Liu and KuoWen Pan," Wireless Sensor Networks and Their Applications to the Healthcare and Precision Agriculture", InTech: Wireless Sensor Networks, 2011

[20] Herman Sahota, Ratnesh Kumar, Ahmed Kamal, Jing Huang, "An Energy- efficient Wireless Sensor Network for Precision Agriculture", Conference on Computers and Communications, 347-350, 2010

[21] Sonal Verma, Nikhil Chug, Dhananjay V. Gadre, "Wireless Sensor Network for Crop Field Monitoring", International Conference on Recent Trends in Information, Telecommunication and Computing, 207211,2010

[22] Daniel R. Kindreda, Tamara M.O. Verhoevena, Richard M. Weightmana, J. Stuart Swanstonb, Reginald C. Aguc,
James M. Brosnanc, Roger Sylvester-Bradley, "Effects of variety and fertilizer nitrogen on alcohol yield, grain yield, starch and protein content, and protein composition of winter wheat", Journal of Cereal Science, 48:46-57, 2007

[23] C.Daniel and E. Triboi, "Effects of Temperature and Nitrogen Nutrition on the Grain Composition of Winter Wheat: Effects on Gliadin Content and Composition", Journal of Cereal Science, 32:45-36, 2000

[24] Murut Dener, Cevat Bostancigloglu, "Smart Technologies with Wireless Sensor Networks",Procedia Social and Behavioral Sciences, 195:1915-1921, 2015

[25] Lion Doron, "How Computer Controlled Fertigation Overcomes Fertilization Challenges", 2014.

\section{AUTHORS PROFILE}

Santosh is pursuing Ph.D (Computer Science and Engineering) from RKDF University, Bhopal, India. He has completed M.E. from Marathwada Institute of Technology, Aurangabad in 2012. His primary research areas of interest include Networking, Systems and many more.

Dr. Ravi Singh Pippal is presently working as a Professor (Computer Science and Engineering) in RKDF University, Bhopal, India. $\mathrm{He}$ has obtained $\mathrm{Ph} . \mathrm{D}$ from ABV-Indian Institute of Information Technology and Management, Gwalior. His primary research areas of interest include Cryptology, Steganography, Key Management, Image Encryption, Fuzzy Logic and many more. 